\title{
Genetic progress in popcorn recurrent selection by a multivariate mixed-model approach
}

\author{
Progresso genético na seleção recorrente em milho pipoca \\ via abordagem de modelos mistos multivariado
}

\author{
${ }^{1}$ Universidade Federal de Lavras/UFLA, Departamento de Biologia/DBI, Lavras, MG, Brasil \\ ${ }^{2}$ University of Florida, Horticultural Science Department, Gainesville, Florida, USA \\ *Corresponding author: so_hugo85@yahoo.com.br \\ Received in June 18, 2017 and approved in January 31, 2018
}

Hugo Junqueira Ematné1*, José Airton Rodrigues Nunes ${ }^{1}$, João Cândido de Souza ${ }^{1}$ Patrício Ricardo Muñoz

\begin{abstract}
Recurrent selection is a viable alternative for popcorn breeding. However, frequent verification of progress attained is required. The aim of this study was to estimate the genetic progress attained for popping expansion (PE) and grain yield (GY) after four cycles of recurrent selection and to compare this progress with the expected progress estimated at the end of each cycle while considering the genetic relationships between the progenies via univariate and multivariate mixed-model approaches. To estimate the genetic parameters and gains from indirect selection, cycles 1, 2, 3, and 4 of a UFLA population were used. To estimate the genetic gains achieved, the following cycles were used: UFLA (original) and cycles 0, 1, 2, 3, and 4, evaluated in three environments. The multivariate approach provided more accurate estimates than did the univariate approach. There was genetic gain for PE in the recurrent selection program. In contrast, gain was not observed for GY using the different estimation strategies.
\end{abstract}

Index terms: Plant breeding; grain yield; popping expansion.

\section{RESUMO}

A seleção recorrente é uma alternativa viável para o melhoramento da cultura do milho pipoca, todavia faz-se necessário verificar frequentemente o progresso obtido. O objetivo do presente trabalho foi estimar o progresso genético realizado para capacidade de expansão (PE) e rendimento de grãos (GY) após quatro ciclos de seleção recorrente e comparar com o progresso esperado, estimado ao final de cada ciclo, levando em consideração o relacionamento genético entre as progênies, via abordagem de modelos mistos univariada e multivariada. Na estimação dos parâmetros genéticos e ganhos com a seleção por via indireta, utilizou-se os ciclos 1, 2, 3 e 4 da população UFLA. Na estimação dos ganhos realizados, foram usados os seguintes ciclos: UFLA (original), e os ciclos 0, 1, 2, 3 e 4, avaliados em três ambientes. A abordagem multivariada proporcionou estimativas mais acuradas em relação à univariada. Houve ganho genético para PE no programa de seleção recorrente. Contrariamente, não foi observado ganho para GY usando as diferentes estratégias de estimação.

Termos para indexação: Melhoramento de plantas; rendimento de grão; capacidade de expansão.

\section{INTRODUCTION}

In popcorn breeding, two traits are extremely important: grain yield (GY) and popping expansion (PE). Due to the complex genetic architecture of these traits and combined with the considerable influence of environmental factors, the use of recurrent selection has proven to be an effective strategy for improving populations and leads to a relatively high chance of selecting genotypically superior individuals (Freitas et al., 2013; Rodovalho et al., 2014; Freitas et al., 2014; Pena et al., 2016).

The popcorn breeding program has been conducted by Universidade Federal de Lavras (UFLA) since 2006 based on a local population (UFLA population). This population is characterized as segregating for grain type and is broadly adapted to local growing conditions; however, this population presents low PE values. As a strategy, the breeding program has used intra-population recurrent selection (IRS), prioritizing the PE trait during the first selections and considering GY during the second cycle via tandem selection. In an IRS program, the goal is to increase the mean value per se over the selection cycles via the generation of a promising recombination of genes related to the target traits of the breeding activity. Since this strategy involves a long-term breeding program, it is necessary to periodically measure the genetic progress obtained to evaluate the efficiency of the techniques implemented and assist in the decision-making process in the future (Breseghello et al., 2011). 
In relation to genetic progress, we must distinguish between expected progress based on the coefficient of heritability and on the selection differential in contrast with the progress obtained in relation to the genetic gain achieved, after having passed through the recurrent selection cycles (Falconer; Mackay, 1996). Traditionally, estimates of these genetic parameters have been obtained using a fixed-model approach via the least squares method (LSM). This approach continues to offer great assistance to breeding programs, especially in annual crops, owing to the less imbalance of phenotypic data (Piepho et al., 2008). However, when there is an extensive imbalance in the data and/or complex pedigree information among genotypes, the LSM presents some limitations. In these cases, the use of a more robust procedure is needed, such as a mixed-model approach (Resende, 2007).

The REML/BLUP (restricted maximum likelihood/ best linear unbiased predictor) procedure can adequately address unbalanced data and includes information on genetic relationships within a model, leading to more accurate estimates and predictions (Henderson, 1974). Another important question is whether to carry out selection considering two or more traits simultaneously. In this case, the univariate REML/BLUP procedure does not allow exploitation of genetic and phenotypic correlations that may exist and may generate bias in the estimates. To solve this problem, Henderson and Quaas (1976) introduced a multivariate mixed-model analysis, which has been used for some time in animal breeding (Meyer; Thompson, 1986; Waldman; Ericsson, 2006). However, in annual crops such as maize, studies using this approach are still rare (Kurosawa et al., 2017; Balestre et al., 2012; Viana et al., 2010; Piepho et al., 2008).

The aim of this study was to estimate the genetic progress undertaken for PE and GY after four recurrent selection cycles and to compare the progress with the gain expected from selection at the end of each cycle, taking the genetic relationship between the progenies into consideration via univariate and multivariate mixed-model approaches.

\section{MATERIAL AND METHODS}

\section{Description of the recurrent selection program}

The popcorn breeding program began in the 2005/2006 cropping season with the multiplication of the UFLA population and subsequent selection of 400 plants to obtain the UFLA population (base population). With this population, recurrent breeding procedures began with selection and recombination, producing cycles $0 \_1,1,2$, 3 , and 4 as described below.
The UFLA 0_1 cycle consisted of 40 half-sib progenies obtained by evaluation for the PE trait among the 400 half-sib progenies of the UFLA 0 population and by selection of the 40 best ones. The UFLA 1 (cycle 1) cycle consisted of 536 half-sib progenies obtained from the recombination of the 40 best half-sib progenies for the PE trait of the UFLA 0_1 population, and the UFLA 2 (cycle 2) cycle consisted of 394 half-sib progenies obtained from the recombination of the 42 best half-sib progenies for the PE trait of the UFLA 1 population. The UFLA 3 (cycle 3) cycle consisted of 560 half-sib progenies obtained from the recombination of the 42 best half-sib progenies for the PE and GY traits of the UFLA 2 population, and the UFLA 4 (cycle 4) consisted of 650 half-sib progenies obtained from the recombination of the 24 best half-sib progenies for the PE and GY traits of the UFLA 3 population. At the end of each recombination cycle, equal seed samples of all the plants were taken and stored to represent their respective cycles.

The progenies selected at the end of the evaluations within a cycle were recombined according to the modified Irish method (establishing the recombination lot in a completely randomized block design with three replications) to obtain the next generation. All the evaluations for PE and GY were carried out for all the plants of the recombination lot, respecting their respective progenies. The recombination lots were established on the UFLA experimental farm in the municipality of Ijaci, MG, during the 2007/2008, 2008/2009 and 2009/2010 cropping seasons.

\section{Estimation of the indirect progress of recurrent selection by the uni- and multivariate mixed-models approaches}

In the present study, UFLA 1, UFLA 2, UFLA 3, and UFLA 4 populations were used. The traits evaluated were PE and GY. The PE values were obtained by the ratio between the volume of expanded popcorn and the weight of the grains $\left(\mathrm{ml} \mathrm{g}^{-1}\right)$. For each progeny, a ten-gram grain sample was evaluated in an $800 \mathrm{~W}$ microwave oven for 150 seconds, according to the modified method described by Matta and Viana (2003). The expanded popcorn was measured in a $1000 \mathrm{ml}$ graduated cylinder. The GY trait was obtained individually by weighing a certain volume of grain per plant on a precision scale. Recombination among selected progenies was performed in the field (isolated in time) according to the modified Irish method at the UFLA experimental farm in the municipality of Ijaci, MG. The recombination involved a randomized block design (RBD) with three replications in the 2007/2008, 2008/2009, and 2009/2010 cropping seasons. 


\section{REML/BLUP analyses:}

The individual model adopted for the univariate analysis was similar to that presented by Mrode and Thompson (2005) and is given in Equation 1 as:

$y=X \beta+Z a+e$,

where $y$ is the vector of the individual phenotypic data; $\beta$ is the vector of the fixed effects of the blocks added to the overall mean value; $a$ is the vector of the individual additive genetic effects $\left(a \sim \operatorname{NMV}(0, \mathrm{G})\right.$, with $\left.\mathrm{G}=A \sigma_{a}^{2}\right) ; \mathrm{X}$ and $\mathrm{Z}$ are the incidence matrices of the fixed and random effects, respectively; and $\mathrm{e}$ is the residual vector $\left(\mathrm{e} \sim \operatorname{NMV}(0, \mathrm{R})\right.$, with $\left.\mathrm{R}=\mathrm{I} \sigma_{e}^{2}\right)$.

For the previously described mixed model (Equation 1), "A" refers to the matrix of the additive genetic relationship (the kinship coefficients were computed as two times the Malecot's coefficient), 0 refers to the null vector, I refers to the identity matrix, $\sigma_{a}^{2}$ is the additive variance, and $\sigma_{e}^{2}$ is the residual variance.

The matrices of the system of Henderson's mixed model equations can be given in Equation 2 as (Mrode; Thompson, 2005):

$$
\left[\begin{array}{l}
\hat{\beta} \\
\hat{a}
\end{array}\right]=\left[\begin{array}{cc}
X^{\prime} R^{-1} X & X^{\prime} R^{-1} Z \\
Z^{\prime} R^{-1} X & Z^{\prime} R^{-1} Z+G^{-1}
\end{array}\right]^{-1}\left[\begin{array}{c}
X^{\prime} R^{-1} y \\
Z^{\prime} R^{-1} y
\end{array}\right] .
$$

The individual multivariate model adopted was similar to that presented by Mrode and Thompson (2005, p. $85)$, which can be given as follow for traits 1 (grain yield) and 2 (popping expansion) in Equations 3 and 4, respectively:

$y_{1}=X_{1} \beta_{1}+Z_{1} a_{1}+e_{1}$,

$y_{2}=X_{2} \beta_{2}+Z_{2} a_{2}+e_{2}$.

In matrix terms, models showed in Equations 3 and 4 can be expanded to Equation 5:

$\left[\begin{array}{l}y_{1} \\ y_{2}\end{array}\right]=\left[\begin{array}{cc}X_{1} & 0 \\ 0 & X_{2}\end{array}\right]\left[\begin{array}{l}\beta_{1} \\ \beta_{2}\end{array}\right]+\left[\begin{array}{cc}Z_{1} & 0 \\ 0 & Z_{2}\end{array}\right]\left[\begin{array}{l}a_{1} \\ a_{2}\end{array}\right]+\left[\begin{array}{l}e_{1} \\ e_{2}\end{array}\right]$.

The matrices of the system of multivariate mixed model equations are similar to the univariate approach (Equation 2);

$\hat{\beta}=\left[\begin{array}{l}\hat{\beta}_{1} \\ \hat{\beta}_{2}\end{array}\right], \quad \hat{a}=\left[\begin{array}{l}\hat{a}_{1} \\ \hat{a}_{2}\end{array}\right], \quad R=I \otimes\left[\begin{array}{cc}\sigma_{e 1}^{2} & \sigma_{e 12} \\ \sigma_{e 12} & \sigma_{e 2}^{2}\end{array}\right]$,
$\mathrm{G}=A \otimes\left[\begin{array}{cc}\sigma_{a 1}^{2} & \sigma_{a 12} \\ \sigma_{a 12} & \sigma_{a 2}^{2}\end{array}\right], \sigma_{\mathrm{e} 12}$ is the additive covariance between traits 1 and $2, \sigma_{\mathrm{e} 12}$ is the residual covariance between traits 1 and 2 , and $\otimes$ is the Kronecker product.

The individual univariate and multivariate models involving all the generations (combined analysis) were given by the models described in Equations 1 and 5, respectively. However, in this case, the $\beta$ vector refers to the fixed effects of the blocks added to the overall mean and of the environment/cycle effects.

The REML method was applied to estimate the covariance components and their significance was verified by REML-likelihood ratio test (REML-LRT) at the $5 \%$ probability level. The heritabilities at the individual level were obtained by Equation 6 and their standard errors were obtained according to Gilmour et al. (2009).

$h^{2}=\frac{\hat{\sigma}_{a}^{2}}{\hat{\sigma}_{a}^{2}+\hat{\sigma}_{e}^{2}}$.

The predictive accuracy was obtained by Equation 7 , as follows:

$r_{\tilde{a} a}=\sqrt{1-\left(\frac{P E V}{\hat{\sigma}_{a}^{2}}\right)}$

where PEV is the prediction error variance (Mrode; Thompson, 2005).

The expected genetic gains were obtained from BLUP values associated with genetic effects by generation and all generations for PE and GY using the two approaches (the uni- and multivariate ones).

All analyses were performed using the software ASReml 3.0 (Gilmour; Gogel; Cullis, 2009).

\section{Estimation of the genetic progress of recurrent} selection by the least squares method

The populations UFLA 0 , UFLA $0 \_1$, UFLA 1 , UFLA 2, UFLA 3, and UFLA 4 as well as two commercial controls (IAC 112 and IAC 125) were used to conduct this experiment. These cycles, represented by an equal mixture of seeds from all the plants, were evaluated in three environments: Environment 1, the UFLA experimental farm in the municipality of Ijaci, MG, in the 2010/2011 cropping season; Environment 2, the experimental field of the Department of Biology of the UFLA in the municipality 
of Lavras, MG, in the 2010/2011 cropping season; and Environment 3, the experimental field of the Department of Biology of the UFLA in the municipality of Lavras, MG, in the 2008/2009 cropping season.

In all the environments, a randomized block experimental design was used consisting of 7, 4, and 11 replications in environments 1,2 , and 3 , respectively. The plots consisted of two 3-m rows at a spacing of $0.6 \mathrm{~m}$, with five plants $\mathrm{m}^{-1}$. The traits evaluated per plot in the three environments were as follows: GY (in tons per hectare), which was obtained from grain weight per plot followed by subsequent transformation to tons per hectare and corrected both for ideal stand per plot by the covariance method (Vencovsky; Cruz, 1991) and for a standard moisture of $13 \%$; PE (in $\mathrm{ml} \mathrm{g}^{-1}$ ), which was obtained by the ratio between the volume of expanded popcorn and grain weight. In each plot, three samples of $30 \mathrm{~g}$ of grain were evaluated in an $800 \mathrm{~W}$ microwave oven for three minutes (180 seconds) according to the modified model described by Matta and Viana (2001). The PE was measured in a $1000 \mathrm{ml}$ graduated cylinder.

For the traits evaluated, the basic assumptions for carrying out the analysis of variance (ANOVA) were first verified. Upon meeting these requirements, individual ANOVAs were carried out with additional controls, considering the mean value per plot (Cruz, 2006; Ramalho; Ferreira; Oliveira, 2005). To carry out combined ANOVAs with additional controls, each trait was examined by the Hartley test to verify if the residual mean squares over the environments were homogeneous (Cruz, 2006; Ramalho; Ferreira; Oliveira, 2005). For the estimation of genetic gain attained in the selection cycles, we used the estimates of the population mean in each cycle for the PE and GY traits and applied the least squares method. For carrying out the analyses, SAS $^{\circledR}$ (SAS Institute, 2002) statistical software was used.

\section{RESULTS AND DISCUSSION}

\section{Estimate of genetic parameters and progress per selection cycle}

In the cycles evaluated (Tables 1 and 2), genetic variability $(\mathrm{P}<0.05)$ is observed from the results of the uni- and multivariate approaches. This variability is indispensable for the success of a recurrent selection program as generations advance.

The estimates of the additive genetic $\left(\sigma_{a}^{2}\right)$ and residual $\left(\sigma_{e}^{2}\right)$ variances between the univariate and multivariate analyses were similar (Tables 1 and 2); the multivariate approach was slightly superior than the univariate approach (greater estimates of $\sigma_{a}^{2}$ and lower $\sigma_{e}^{2}$ ), except for PE in cycle 3.

Experimental precision was verified by the estimates of the predictive accuracy, which allows us to compare the approaches to identify which approach provides more accurate estimates. The multivariate approach in general exhibited greater precision (greater predictive accuracy) in all the cycles, except for PE during cycle 3 and in the combined analysis. However, this lower precision in the combined analysis is due to the four cycles considered in the univariate analysis $(\mathrm{C} 1, \mathrm{C} 2$, $\mathrm{C} 3$, and $\mathrm{C} 4$ ), whereas multivariate analysis considers only three (C2, C3, and C4), which are the cycles in which PE and GY are evaluated (Tables 1 and 2). When we analyze only the three cycles $(\mathrm{C} 2, \mathrm{C} 3$, and $\mathrm{C} 4)$ by the univariate approach, which is the more correct comparison, the results of the multivariate analysis were $1 \%$ better (data not shown). The multivariate analysis revealed estimates of predictive accuracy that were $58 \%$ and $1.5 \%$ better than those from the univariate analysis during cycle 2 for PE and GY, respectively; $26.6 \%$ better estimates during cycle 3 for GY, 7\% and $4.5 \%$ better estimates during cycle 4 for PE and GY, respectively; and $18.3 \%$ better means of the cycles for GY (combined analysis), indicating that, in these cases, the multivariate analysis surpassed the univariate analysis, despite being penalized by one less cycle. The estimates of heritabilities between the two analyses were similar, with distortion only in cycle 3 for $\mathrm{PE}$, in which the univariate analysis proved to be more advantageous. The estimates of heritability for PE were of medium to high magnitude, oscillating from 0.25 to 0.82 from the univariate approach and from 0.26 to 0.62 from the multivariate approach. For GY, the estimates were of low to medium magnitude, ranging from 0.19 to 0.42 and 0.19 to 0.43 from the univariate and multivariate approaches, respectively.

As the selections made at the beginning of the program prioritized the PE trait apart from the GY trait, gains for the two traits simultaneously will depend on the genetic relationship between them. Consequently, the estimates of genetic correlation $\left(r_{g}\right)$ will show how related the traits are. The estimates of $r_{g}$ were obtained by the multivariate approach (Table 2), which indicated a negative association only during cycle 4 . The overall mean of the cycles (combined analysis), which corrects the effects of the cycle and enables a mean estimate of the genetic correlation to be obtained, was $r_{g}=0.11$; as such, on average, the traits were independent. 


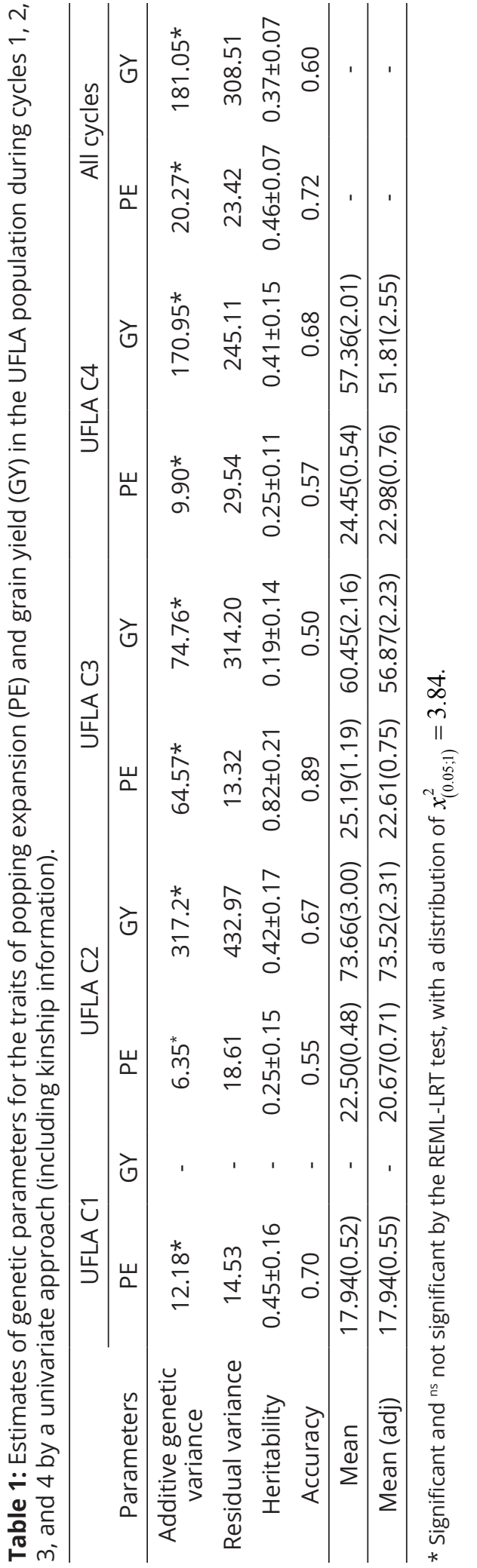

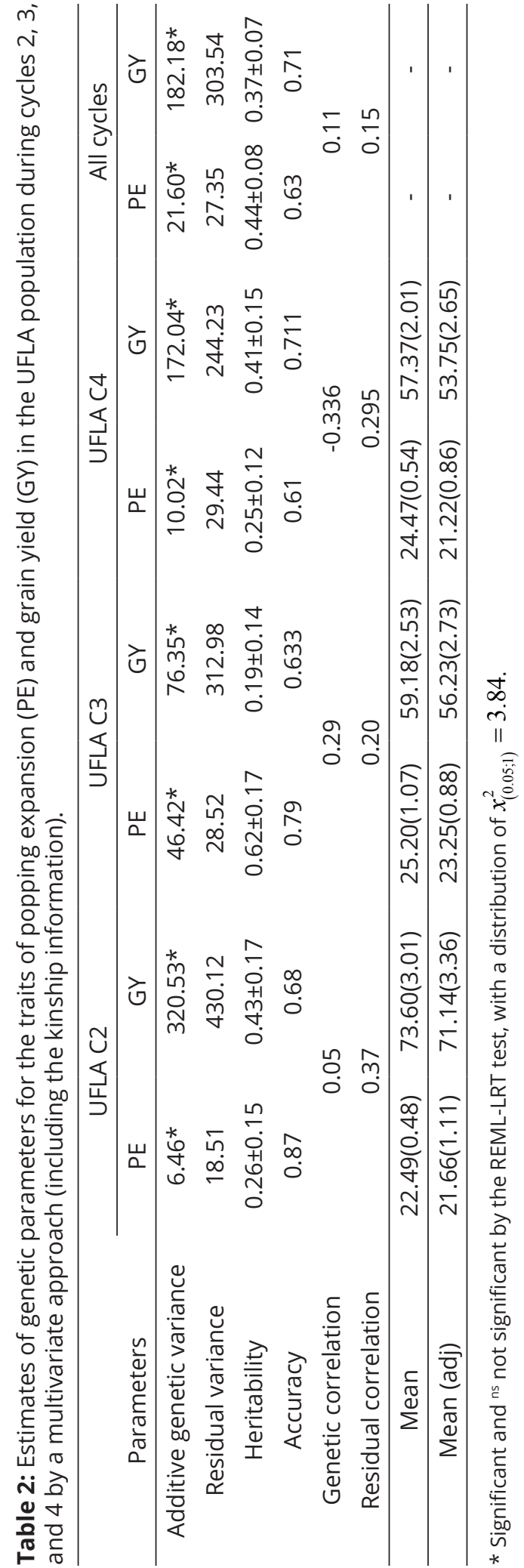

Ciência e Agrotecnologia, 42(2):159-167, Mar/Apr. 2018 
The gains estimated from selection were obtained using regression analysis, with the phenotypic mean values adjusted per cycle in the combined analysis for both approaches. From the univariate approach, the gains were $2.3 \% 7$ and $-3.7 \%$ for PE and GY, respectively, per selection cycle, and from the multivariate approach, the gains were $-0.33 \%$ and $-3.74 \%$ for PE and GY, respectively.

\section{Direct gain from selection (least squares method)}

From the ANOVA (data not shown), significant variation was observed between the selection cycles $(\mathrm{P}<0.01)$ for the PE trait; no variation in the cycle $\times$ environment interaction was observed. For GY, significant differences were not observed. Figure 1 represents the evaluation of all the selection cycles undertaken across the three environments using the mean values adjusted by the combined analysis for
PE and GY. An increase of 1.4\% was observed for PE, and a stable response was observed for GY (Figure 1).

\section{Discussion}

In the approaches evaluated, the accuracies were in the range of $55 \%$ to $89 \%$ from the univariate analysis and from $61 \%$ to $87 \%$ from the multivariate analysis, which indicates moderate to high precision (Resende; Duarte, 2007). Predictive accuracy increases to the extent that the absolute deviations between the parametric genetic values and the predicted genetic values are lower, that is, the lower the prediction error variance (PEV) is, the more accurate the estimator (Resende; Duarte, 2007). In this study, with few exceptions, the multivariate approach provided more accurate estimates.

According to Piepho et al. (2008), the application of the multivariate BLUP method has advantages over the univariate
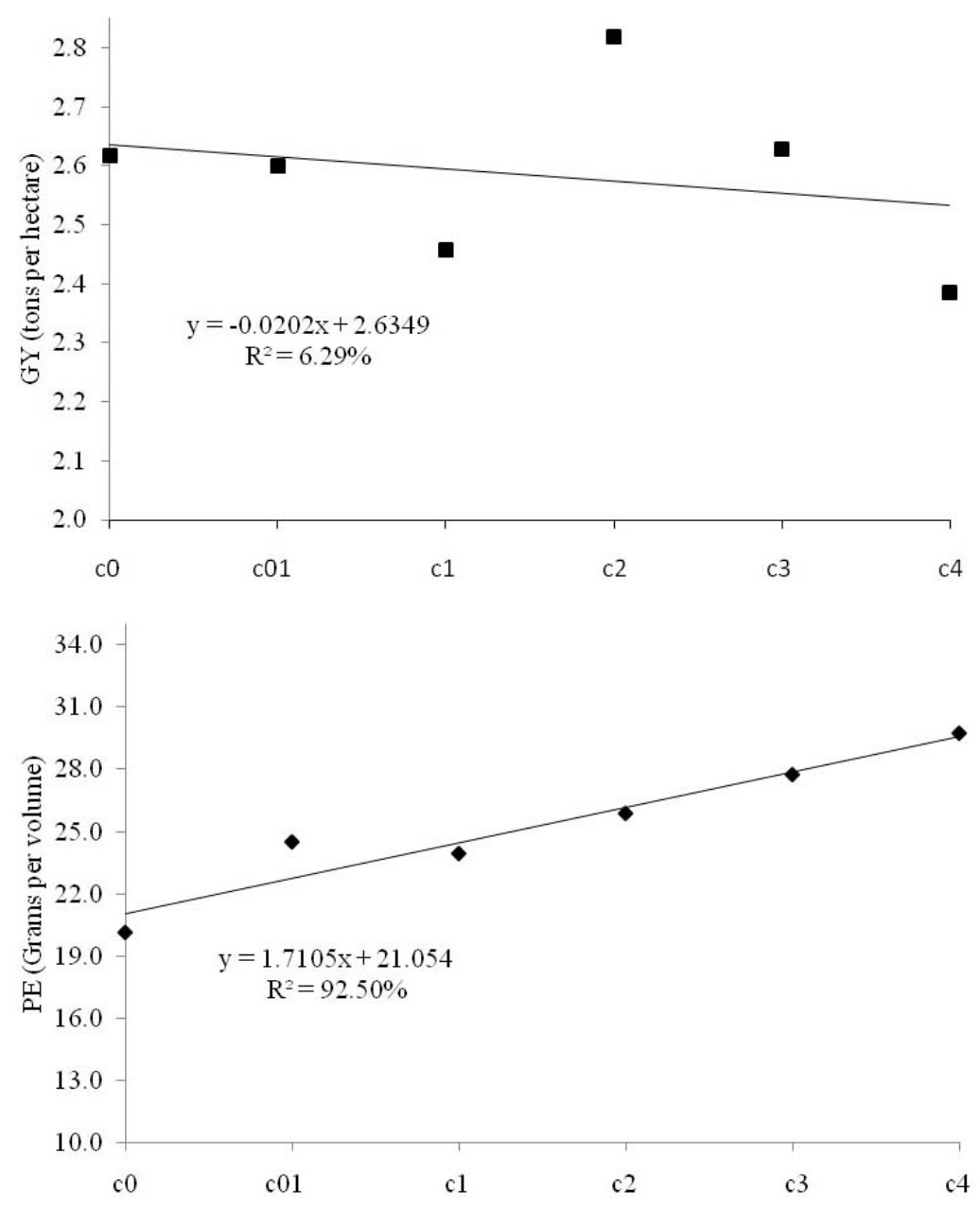

Figure 1: Phenotypic means adjusted by the least squares method by selection cycle in three environments for the traits of popping expansion (PE) and grain yield (GY) of the UFLA populations. 
method when the traits involved in the analysis exhibit high genetic correlation. Nevertheless, some authors have reported that the increase in precision obtained using the multivariate BLUP method is proportional to the absolute difference between the genetic and environmental correlations of the traits (Schaeffer, 1984; Thompson; Meyer, 1986; Resende, 2007). Additionally, Bauer and Léon (2008) similarly confirmed via simulations for two traits with different heritabilities ( 0.3 and $0.7)$ and via scenarios of genetic and residual correlations that multivariate analysis exhibited lower prediction error and that the superiority of multivariate analysis in relation to univariate analysis is more expressive when the traits are negatively correlated. In this context, the multivariate method for the estimation of genetic parameters in popcorn would be preferred because of the existence of negative correlations between PE and GY (frequently reported in the literature), to a greater or lesser degree of association, and by the difference in heritability between the two traits (Vieira et al., 2016; Freitas et al., 2014). This phenomenon occurs because the multivariate model specifically considers the environmental and genetic covariances that exist between the traits, minimizing biases that can occur in individual analyses, especially from sequential selection (Resende, 2007).

The estimates of heritability between the two approaches were very similar in this study, although the multivariate approach provided errors that were less than or at least equal to those provided by the univariate approach. Regarding the analysis of all the cycles (combined analysis), the multivariate approach provided better estimates and smaller errors. Viana et al. (2010), working with selection cycles in popcorn for PE and GY, also recommended the multivariate approach, although they did not report superiority of the multivariate approach in relation to the univariate (individual model) approach. The authors further discussed that the heritabilities between the two traits both were similar and showed favorable correlations, and for this reason, the multivariate approached lacked superiority. In relation to genetic gains per cycle, there was a gain for PE from the univariate approach (Figure 2), whereas for GY, gain was observed in a negative sense from both approaches. This finding was expected because selection of the cycles gave priority to PE in the recombination unit, considering GY as only part of the second cycle. Selection was made for grain weight per plant within the highestyielding families in tandem, which, in a certain way, is subject to great environmental influence.

The estimated genetic gains slightly distorted the gains attained when we analyzed the cycles in the same experiment (Figure 2). For PE, the univariate approach overestimated the gains while the multivariate approach underestimated them when we compare those gains with the gains achieved; nevertheless, the multivariate analysis was penalized in cycle 1 , since this analysis did not have involve that cycle. For GY, both approaches indicated a reduction, whereas evaluation of the gains achieved in the field indicated stability as generations advanced. A question that remains is how much the genotype $\times$ environment interaction interferes with the estimates of genetic progress because, when we estimate the progress in an indirect manner, the environmental effect is confounded in the cycle, and when we analyze the progress achieved after all the cycles in some environments, the interaction can mask the results. Following this line of reasoning, Faria et al. (2013) estimated the genetic progress after 22 years of common bean breeding via the EMBRAPA ARROZ E FEIJÃO program for traits in 20 environments. Those authors reported that the genotype $\times$ environment interaction was high, which interferes with the estimation of genetic progress.

Researchers at Universidade Estadual do Norte Fluminense Darcy Ribeiro have been developing a recurrent selection program for some time, prioritizing the PE and GY traits; this program is now in its seventh cycle. As the generations advance, some strategies were adopted in the program, such as mass selection in cycle $0 ; \mathrm{S}_{1}$ families in cycle 2; half-sib families in cycle 3 ; and full-sib families in cycles $1,4,5$, and 6 . The program has been using the index of Mulamba and Mock (1978) as a selection strategy. However, during selection in the sixth cycle, Freitas et al. (2013) compared some selection strategies, concluding that the Mulamba and Mock (1978) index is the most adequate; however, the greatest gains were estimated by the univariate REML/BLUP method. Freitas et al. (2014) then evaluated all the cycles from 0 to 6 and estimated both the genetic parameters of the sixth cycle and the progress from selection for the seventh cycle, obtaining expressive gains for PE and GY.

In summary, greater attention should be given to the GY trait in future cycles together with PE, that is, other breeding strategies should be adopted for the popcorn breeding program of the UFLA, which considers the GY and PE traits simultaneously. This recommendation is because phenotypic selection for PE in the recombination unit is effective at increasing PE but not effective at increasing GY if we consider the gains both achieved and estimated via univariate analyses. An alternative would be to make use of indices obtained by multivariate approaches, which allow possible existing genetic corrections with more accurate predictions to be exploited; another alternative could be the use of the Mulamba and Mock (1978) (index. However, additional care should be given to economic factors. 

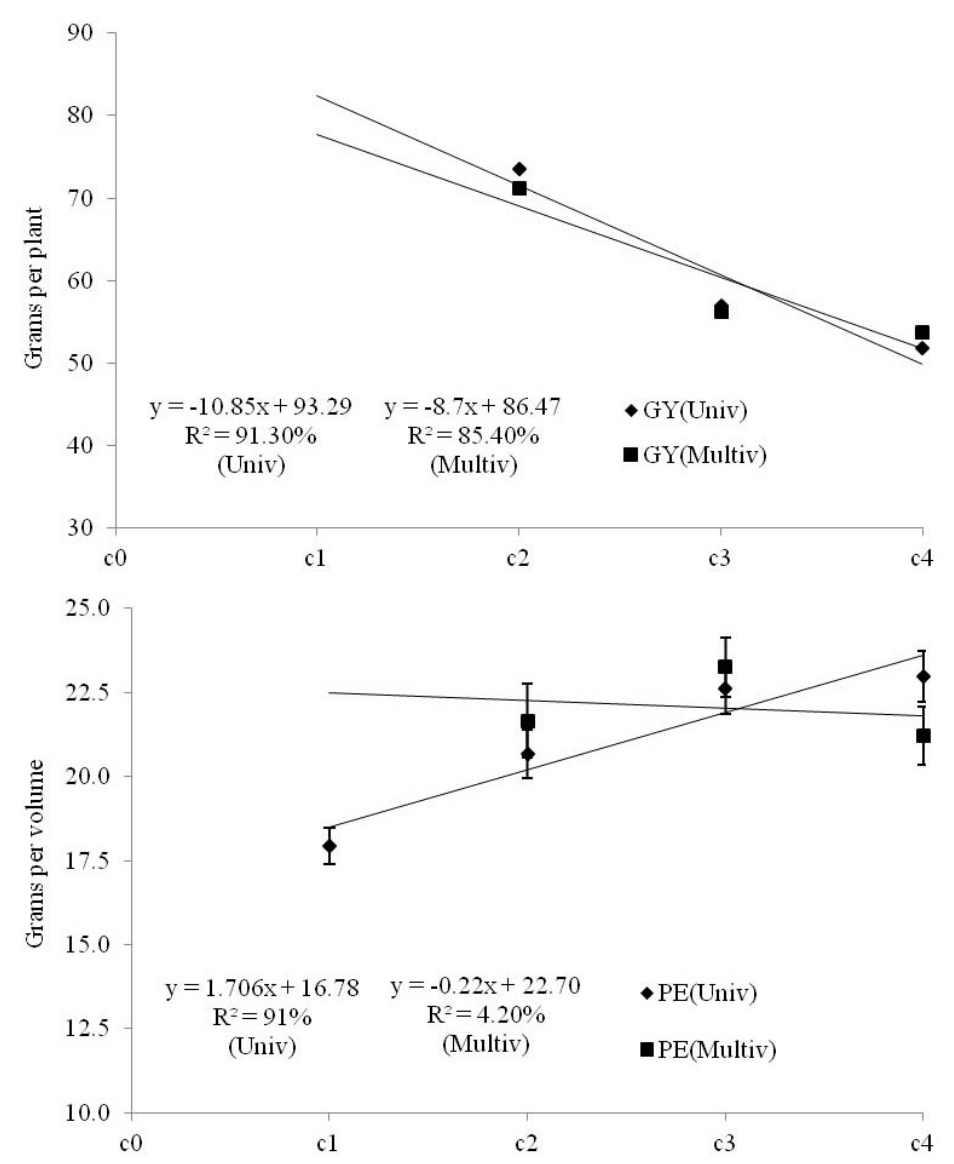

Figure 2: Phenotypic means adjusted per cycle, by univariate and multivariate analysis in the UFLA population in cycles 1, 2, 3, and 4 for the traits of popping expansion (PE) and grain yield (GY).

\section{CONCLUSIONS}

The multivariate mixed-model approach is preferred to the univariate one because the former is more informative and accurate for the estimation of both genetic parameters and selection gains in popcorn crops with respect to PE and GY traits. Genetic gain for PE occurred as a result of our popcorn recurrent selection program. This gain, by contrast, was not observed for GY using different estimation strategies. Both evaluation and selection for the PE and GY traits in the recombination unit are effective at increasing $\mathrm{PE}$ but are not effective at increasing GY.

\section{REFERENCES}

BALESTRE, M. et al. Applications of multi-trait selection in common bean using real and simulated experiments. Euphytica, 189(2):225-238, 2012.
BAUER, A. M.; LÉON, J. Multiple-trait breeding values for parental selection in self-pollinating crops. Theoretical and Applied Genetics, 116(2):235-242, 2008.

BRESEGHELLO, F. et al. Results of 25 years of upland rice breeding in Brazil. Crop Science, 51(3):914-923, 2011.

CRUZ, C. D. Programa Genes: Análise multivariada e simulação. Viçosa, MG: UFV, 2006. 175p.

FARIA, L. C. et al. Genetic progress during 22 years of improvement of carioca-type common bean in Brazil. Field Crops Research, 142:68-743, 2013.

FREITAS, I. L. J. et al. Ganho genético avaliado com índices de seleção e com REML/Blup em milho-pipoca. Pesquisa Agropecuária Brasileira, 48(11):1464-1471, 2013.

FREITAS, I. L. J. et al. Genetic gains in the UENF-14 popcorn population with recurrent selection. Genetics and Molecular Research, 13(1):518-527, 2014. 
GILMOUR, A. et al. ASReml user guide, release 3.0. Hemel Hempstead: VSN International, 2009. 320p.

HENDERSON, C. R. General flexibility of linear model techniques for sire evaluation. Journal of Dairy Science, 57:963-972, 1974.

HENDERSON, C. R.; QUAAS, R. L. Multiple trait evaluation using relatives' records. Journal of Animal Science, 43:11881197,1976

KUROSAWA, R. N. F. et al., Multivariate approach in popcorn genotypes using the Ward MLM strategy: Morphoagronomic analysis and incidence of Fusarium spp. Genetics and Molecular Research, 16(1)1-12, 2017.

MATTA, F. P.; VIANA, J. M. S. Eficiências relativas de seleção entre e dentro de famílias de meios-irmãos em população de milho-pipoca. Ciência e Agrotecnologia, 27(3):548556, 2003.

MEYER, K.; THOMPSON, R. Sequential estimation of genetic and phenotypic parameters in multitrait mixed model analysis. Journal of Dairy Science, 69(10):2696-2703, 1986.

MRODE, R. A.; THOMPSON, R. Linear models for the prediction of animal breeding values. Wallingford: CABI, 2005. 344p.

MULAMBA, N. N.; MOCK, J. J. Improvement of yield potential of the Eto Blanco maize (Zea mays L.) population by breeding for plant traits. Egyptian Journal of Genetics and Cytology, 7:40-51, 1978.

PENA, G. F. et al. Comparação de testadores na seleção de famílias S3 obtidas da variedade UENF-14 de milho-pipoca. Bragantia, 75(2):135-144, 2016.

PIEPHO, H. P. et al. BLUP for phenotypic selection in plant breeding and variety testing. Euphytica, 161(1/2):209228, 2008.

RAMALHO, M.A. P.;FERREIRA, D. F.; OLIVEIRA, A. C. Experimentação em genética e melhoramento de plantas. Lavras: UFLA, 2005. 322p
RESENDE, M. D. V. Matemática e estatística na análise de experimentos e no melhoramento genético. Colombo: EMBRAPA Florestas, 2007. 362p.

RESENDE, M. D. V. de; DUARTE, J. B. Precisão e controle de qualidade em experimentos de avaliação de cultivares. Pesquisa Agropecuária Tropical, 37(3):182-194, 2007.

RODOVALHO, M. et al. Genetic evaluation of popcorn families using a Bayesian approach via the independence chain algorithm. Crop Breeding and Applied Biotechnology, 14:261-265, 2014

SCHAEFFER, L. R. Sire and cow evaluation under multiple traits model. Journal of Dairy Science, 67(7):1567-1580, 1984.

SOARES, A. A.; RAMALHO, M. A. P.; SOUSA, A. F. de. Estimativa do progresso genético obtido pelo programa de melhoramento de arroz irrigado da EPAMIG, na época de oitenta. Pesquisa Agropecuária Brasileira, 29:97-104, 1994.

STATISTICAL ANALYSIS SYSTEM INSTITUTE. SAS/STAT User'S guide. Version 9. Cary, Software, 2002.

THOMPSON, R.; MEYER, K. A review of theoretical aspects in the estimation of breeding values for multi-trait selection. Livestock Production Science, 15(4):299-313, 1986.

VENCOVSKY, R.; CRUZ, C. D. Comparação de métodos de correção do rendimento de parcelas com estandes variados: I. Dados simulados. Pesquisa Agropecuária Brasileira, 26(8):647-657, 1991.

VIANA, J. M. S. et al. Multi-trait BLUP in half-sib selection of annual crops. Plant Breeding, 129(6):599-604, 2010.

VIEIRA, R. A. et al. Selection index based on the relative importance of traits and possibilities in breeding popcorn. Genetics and Molecular Research, 15(2), 2016.

WALDMANN, P.; ERICSSON, T. Comparison of REML and Gibbs sampling estimates of multi-trait genetic parameters in Scots pine. Theoretical and Applied Genetics, 112(8):1441-1451, 2006. 